\title{
Fas/FasL-mediated apoptosis and inflammation are key features of acute human spinal cord injury: implications for translational, clinical application
}

\author{
Wen Ru Yu • Michael G. Fehlings
}

Received: 8 July 2011/Revised: 28 September 2011/Accepted: 29 September 2011/Published online: 29 October 2011

(C) The Author(s) 2011. This article is published with open access at Springerlink.com

\begin{abstract}
The Fas/FasL system plays an important role in apoptosis, the inflammatory response and gliosis in a variety of neurologic disorders. A better understanding of these mechanisms could lead to effective therapeutic strategies following spinal cord injury (SCI). We explored these mechanisms by examining molecular changes in postmortem human spinal cord tissue from cases with acute and chronic SCI. Complementary studies were conducted using the in vivo Fejota ${ }^{\mathrm{TM}}$ clip compression model of SCI in Fas-deficient B6.MRL-Fas-lpr (lpr) and wild-type (Wt) mice to test Fas-mediated apoptosis, inflammation, gliosis and axonal degeneration by immunohistochemistry, Western blotting, gelatin zymography and ELISA with Mouse 32-plex cytokine/chemokine panel bead immunoassay. We report novel evidence that shows that Fasmediated apoptosis of neurons and oligodendrocytes occurred in the injury epicenter in all cases of acute and subacute SCI and not in chronic SCI or in control cases. We also found significantly reduced apoptosis, expression of GFAP, NF- $\mathrm{B}$, p-IKappaB and iba1, increased number of CD4 positive T cells and MMP2 expression and reduced neurological dysfunction in $l p r$ mice when compared with Wt mice after SCI. We found dramatically reduced
\end{abstract}

\section{W. R. Yu}

Division of Genetics and Development,

Toronto Western Research Institute and Krembil Neuroscience Centre, Toronto Western Hospital, University Health Network,

Toronto, ON M5T 2S8, Canada

\section{G. Fehlings ( $\square)$}

Division of Neurosurgery, Toronto Western Research Institute and Krembil Neuroscience Centre,

The Toronto Western Hospital, University Health Network,

Room 4W-449, 399 Bathurst Street, Toronto,

ON M5T 2S8, Canada

e-mail: Michael.Fehlings@uhn.on.ca inflammation and cytokines and chemokine expression in B6.MRL-Fas-lpr mice compared to Wt mice after SCI. In conclusion, we report multiple lines of evidence that Fas/ FasL activation plays a pivotal role in mediating apoptosis, the inflammatory response and neurodegeneration after SCI, providing a compelling rationale for therapeutically targeting Fas in human SCI.

Keywords Fas/FasL - Apoptosis - Inflammation · Cytokine/chemokine $\cdot$ SCI

\section{Introduction}

Spinal cord injury (SCI) causes the shearing of cell membranes and axons, disruption of the blood-spinal cord barrier, cell death, immune cell transmigration, and myelin degradation [4-7, 9, 34]. It also triggers a cascade of secondary damage including vascular permeability, infiltration of peripheral inflammatory cells, activation of astrocytes and microglia, release of pro-inflammatory mediators, demyelination and axonal damage [37] which progressively destroys an increasing amount of tissue adjacent to the primary lesion [5, 14, 27, 38]. The death receptor Fas and its specific ligand (FasL) have gained widespread recognition as an apoptotic mediator [11, 12, 15-17, 20,32,33] for inducing inflammation by release of pro-inflammatory cytokines [26, 39], causing the migration of neutrophils and macrophages to injury site $[17,31]$ and being involved in $\mathrm{T}$ cell proliferation [28] following SCI as well as maintaining the immune suppressed status in the normal brain. Fas deficiency [11, 44, 45], competitive inhibition of Fas activation, or neutralization of FasL with an anti-FasL antibody can promote neurobehavioral recovery in animal models of stroke, SCI $[1,16,45]$ and cervical spondylotic myelopathy [46]. 
Neutralization of FasL also reduces the initial infiltration of inflammatory cells, creating an inflammatory response that facilitates recovery of locomotor function after SCI [31]. A better understanding of these mechanisms could lead to effective therapeutic strategies following SCI.

In this study, we investigated, for the first time, the importance of the Fas/FasL system in the regulation of neuronal and glial apoptosis, inflammatory cell infiltration, gliosis and axonal regeneration following human SCI. We examined the molecular changes in postmortem human spinal cord tissue after acute, subacute and chronic SCI. To provide a mechanistic basis for these observations, complementary investigations were undertaken in a clinically relevant murine model of SCI using mutant mice deficient in Fas expression. Our results clarify the importance of Fas/ FasL in the pathobiology of human SCI thus providing a strong case for targeting Fas therapeutically in this devastating clinical condition.

\section{Materials and methods}

\section{Human SCI}

Sections of paraffin tissue with $5 \mu \mathrm{m}$ thickness were retrieved from the Spinal Cord Tissue Bank (Table 1: 16 cases of SCI and 6 controls) in the pathology department, University Health Network, Toronto, Canada for Hematoxylin and Eosin and Luxol Fast Blue (H\&E/LFB) staining and immunohistochemistry.

Immunohistochemical analysis in human SCI

After being deparaffinized, sections were treated with microwave in $10 \mathrm{mM}$ citrate buffer, $0.3 \% \mathrm{H}_{2} \mathrm{O}_{2}$, avidin solution and blocked with $1 \%$ BSA and 5\% nonfat milk with $0.3 \%$ Triton $\mathrm{X}-100$ for $1 \mathrm{~h}$. The following primary antibodies were used in this study: anti-Fas and anti-FasL (1:100; Santa Cruz Biotechnology, Santa Cruz, CA) for cell death receptor, activated caspase-3 (1:200, Cell Signaling Technology, Beverly, MA); activated caspase- 9 and caspase-7 (1:150; 1:1,500 Nov Littleton, CO 80160, USA) for apoptosis, anti-PG-M1 (CD68 for phagocytic macrophages of microglial and monocytic: 1:50, Dako, Glostrup, Denmark), anti-ionized calcium binding adaptor molecule 1 (Iba1) for ramified and activated microglia (I:300, Wako pure Chemical Industries, Lid); anti-CD3 (1:200, Dako, Denmark) for the human mature $\mathrm{T}$ lymphocytes; antiCD45 (1:500, BD) for B lymphocytes, anti-MPO (1:50, Dako, Denmark) for oxidative reactivity, and MMP-9 (1:100, Chemicon), a pro-inflammatory protease, in blocking solution overnight at $4^{\circ} \mathrm{C}$. Following extensive
Table 1 Summary of the clinical and neurological data in the human SCI and control cases

\begin{tabular}{|c|c|c|c|c|c|c|}
\hline Case & Age & Sex & Group & $\begin{array}{l}\text { Time between } \\
\text { injury and death }\end{array}$ & $\begin{array}{l}\text { Level of } \\
\text { injury }\end{array}$ & $\begin{array}{l}\text { Cause of } \\
\text { injury }\end{array}$ \\
\hline 1 & 73 & M & Acute & 2 weeks & $\mathrm{C} 1-2$ & Fall \\
\hline 2 & 86 & M & Acute & 3 weeks & $\mathrm{C} 1-2$ & Fall \\
\hline 3 & 37 & M & Acute & 4 weeks & C4-5 & Fall \\
\hline 4 & 82 & M & Subacute & 5 weeks & C5-6 & Sports injury \\
\hline 5 & 68 & M & Subacute & 5 weeks & $\mathrm{C} 7$ & MVA \\
\hline 6 & 29 & M & Subacute & 7 weeks & $\mathrm{T} 12$ & Fall \\
\hline 7 & 68 & $\mathrm{~F}$ & Subacute & 2 months & $\mathrm{T} 5$ & Fall \\
\hline 8 & 67 & M & Subacute & 3.5 months & $\mathrm{C} 2-3$ & Fall \\
\hline 9 & 43 & $\mathrm{~F}$ & Subacute & 3.5 months & C5-6 & MVA \\
\hline 10 & 66 & M & Chronic & 6 months & C5-6 & Fall \\
\hline 11 & 31 & $\mathrm{~F}$ & Chronic & 8 months & $\mathrm{C} 2-3$ & MVA \\
\hline 12 & 19 & M & Chronic & 2 years & $\mathrm{C} 4 / 5$ & Sports injury \\
\hline 13 & 65 & M & Chronic & 3.5 years & $\mathrm{C} 1-2$ & MVA \\
\hline 14 & 69 & M & Chronic & 15 years & $\mathrm{C} 6 / 7$ & Diving accident \\
\hline 15 & 42 & M & Chronic & 24 years & $\mathrm{C} 3 / 4$ & MVA \\
\hline 16 & 45 & M & Chronic & 24 years & $\mathrm{C} 5 / 6$ & Sports injury \\
\hline 17 & 43 & $\mathrm{~F}$ & Control & N/A & N/A & N/A \\
\hline 18 & 36.8 & $\mathrm{~F}$ & Control & N/A & N/A & N/A \\
\hline 19 & 41.7 & $\mathrm{~F}$ & Control & N/A & N/A & N/A \\
\hline 20 & 81.5 & $\mathrm{M}$ & Control & N/A & N/A & N/A \\
\hline 21 & 55 & $\mathrm{~F}$ & Control & N/A & N/A & N/A \\
\hline 22 & 44 & M & Control & N/A & N/A & N/A \\
\hline
\end{tabular}


rinsing in $0.1 \mathrm{M}$ PBS, sections were incubated in biotinylated goat anti-mouse or anti-rabbit antibody (diluted 1:200, Vector Laboratories CA, USA) for $1 \mathrm{~h}$ at room temperature. After incubation with the biotinylated secondary antibody, the avidin-biotin complex (ABC; VECTASTAIN $^{\circledR}$ ABC reagent prepared in advance as described in the kit instructions) and diaminobenzidine (DAB; DAB Peroxidase Substrate Kit, Vector Laboratories) were applied to the sections for visualization of the reaction product. Sections from six nonSCI patients (agematched) were used as normal controls. For negative controls, the primary antibody was omitted or incubated with isotype-matched antibodies (1:100-1:10,000; $\operatorname{IgG})$.

\section{Analysis of apoptosis for Human SCI}

Spinal cord sections were processed for TUNEL labeling $\left(\right.$ ApopTag $^{\circledR}$ ) plus a peroxidase in situ apoptosis detection kit (Chemicon Biotechnology Inc, Temecula, CA), as previously described [13].

\section{In vivo spinal cord injury}

SCI was performed by the Fejota ${ }^{\mathrm{TM}}$ clip compression technique at $\mathrm{T} 5 / 6[24,25]$ with $8.3 \mathrm{~g}$ clip for $1 \mathrm{~min}$ in 8 -week-old female wild-type (Wt) and B6.MRL-Fas-lpr (lpr) mice bought from Jackson Laboratory, Bar Harbor, Maine, as previously described. All protocols were in accordance with the Canadian Council of Animal Care policies and were approved by the animal care committee of the University Health Network.

\section{Biotinylated dextran amine (BDA) tracing of the corticospinal tract (CST) and BDA staining}

To trace the corticospinal tract, Wt and lpr mice $(n=4 /$ group) were anesthetized and had their fur removed by shaving after 8 weeks post-injury. The scalp was incised and the skull overlying the sensorimotor cortex was carefully removed with a dental drill. BDA (molecular weight of 10,000 ) with $10 \%$ in DH2O (Molecular Probes, Eugene, OR) was injected into right sensorimotor cortex with a total of four sites using a $10 \mu \mathrm{l}$ Hamilton microsyringe tipped with a pulled glass micropipette. Coordinates were 1.0 lateral, $0.5 \mathrm{~mm}$ deep to the cortical surface, and $+0.5,-0.2,-0.7$, and $1.0 \mathrm{~mm}$ with respect to Bregma. After the injections were completed, the skin overlying the skull was sutured with 4-0 silk as previously described [13]. Two weeks later, all the animals were deeply anesthetized and then were perfused transcardially with PBS and 4\% paraformaldehyde. The spinal cord was post-fixed overnight and embedded within Tissue-Tek ${ }^{\circledR}$ optimal cutting temperature compound (O.C.T; Sakura Finetek USA, Inc., Torrance, CA). The longitudinal sections of $20 \mu \mathrm{m}$ were cut and washed twice in $0.05 \mathrm{M}$ TBS containing $0.5 \%$ Triton X-100. After two washes in TBS, the sections were incubated with Texas redconjugated streptavidin to visualize BDA containing corticospinal axons for $30 \mathrm{~min}$. The sections were washed and coverslipped with glycerol containing DAPI.

\section{Immunohistochemical analysis for mice}

Wt and $l p r$ mice were perfused transcardially with $4 \%$ paraformaldehyde solution. Spinal cord samples of $1 \mathrm{~cm}$ length centered at the injury site were dissected, post-fixed and embedded. Transverse sections of $14 \mu \mathrm{m}$ were cut, blocked in a blocking solution $(0.3 \%$ Triton X-100, 5\% milk and $1 \%$ BSA in PBS) and incubated with GFAP, F4/ 80, CD4, Iba1, MBP, NF200 and MAP2 antibodies. The slides were incubated with fluorescent Alexa 594 or 488 anti-mouse, anti-rabbit or anti-rat secondary antibodies (1:200; Sigma-Aldrich) for $1 \mathrm{~h}$. Staining specificity was determined both by omitting the primary antibody and by competing the primary antibody with its corresponding peptide prior to incubation.

\section{Western Blotting in Wt and lpr mice}

Spinal cord proteins from Wt and $l p r$ mice $(n=11$ per group for sham, 3, 14 days, $n=5$ for $1,7,70$ days) were individually homogenized in a RIPE buffer (Themo Fisher Scientific, Attawa, Canada) at $4^{\circ} \mathrm{C}$, resolved (20-50 $\mu \mathrm{g}$ per lane) in a $12 \%$ or $7.5 \%$ SDS-polyacrylamide gel at $200 \mathrm{~V}$ and transferred to a nitrocellulose membrane. Membranes were blocked with 5\% nonfat milk for $1 \mathrm{~h}$ and incubated with (1) NF200 (1:1,000; Sigma); (2) MAP2 (1:200, Sigma); (3) $\beta$-III tubulin (1:400, Chemicon); (4) caspase-3 (Cell Signaling Technology); (5) GFAP (1:1,000; Chemicon); (6) Ibal antibody (1:400, Wako Chemicals USA, Inc); (7) CNPase (1:400, Chemicon); (8) NF- $\mathrm{KB}$ (1:400, Chemicon) and (9) Phosphorylation of IKappaB alpha (p-IKappaB) (1:1,000; Cell Signaling Technology) antibodies. Membranes were incubated with mouse $(1: 4,000)$ or rabbit $(1: 2,000)$ secondary antibodies conjugated to horseradish peroxidase. Reaction products were visualized using an ECL Western Blot Detection kit (Amersham Biosciences Inc) and Gel Pro analysis software (Media Cybernetice, Silver Spring, MD) to quantify the amount of protein. Densitometric values were normalized to those of B-actin (1:400; Sigma).

Multiplex analysis of cytokines and chemokines protein expression in mice

A total of $80 \mu \mathrm{l}$ per sample of sham controls, and 3, 14 and 70 days $(n=7$ per group) after SCI in MicroCon 
centrifugation tubes (Millipore) was sent to Eve technology company using the Mouse 32-plex cytokine/chemokine panel Bead Immunoassay. The protein concentrations of 32 chemokines/cytokines were quantified and then analyzed using repeated measures ANOVA and $t$ tests using the SPSS SigmaStat 3.0 statistical package (Aspire Software International, Leesburg, VA).

\section{Zymography}

Zymogram gels consisted of $7.5 \%$ polyacrylamide (native) gel polymerized together with gelatin $(1 \mathrm{mg} / \mathrm{ml})$. After electrophoresis, the gels were washed twice with $2.5 \%$ Triton X-100 and incubated with substrate buffer $(50 \mathrm{mM}$ Tris, $\left.5 \mathrm{mM} \mathrm{CaCl}_{2}, \mathrm{pH} 7.5\right)$ at $37^{\circ} \mathrm{C}$ for $24 \mathrm{~h}$. The zymogram is subsequently stained (commonly with coomassie brilliant blue), and areas of digestion appear as clear bands against a darkly stained background where the substrate has been degraded by the enzyme. Gelatinolytic of MMPs activities were detected as transparent bands on the blue background and quantified using Gel Pro analysis software (Media Cybernetice, Silver Spring, MD).

\section{Behavioral tests}

All behavioral tests were performed by two independent observers in a double-blind manner weekly for 8 weeks after SCI and assessed using the Basso Mouse locomotor rating Scale (BMS) [3].

\section{Cell quantification}

All digital images were captured, in a double-blind manner, from four random fields per section in the injured epicenter of the cross-sections in human SCI and control cases using a Nikon Eclipse E800 light microscope and in Wt and lpr mice using a Zeiss LSM 510 META confocal laser scanning fluorescence microscope. The images were taken at $20 \times$ magnification for CD68, TUNEL, F4/80 and CD4 positive cell counting. We counted digital images of CD68, TUNEL and F4/80 positive cells using Image J software (developed at the National Institute of Health, Bethesda, MD). Values from four random fields were averaged to a single value per case or per animal. The results were expressed as the number of CD68, TUNEL and F4/80 positive cells.

\section{Statistical analysis}

Significant differences in cell counts were analyzed using repeated measures ANOVA and $t$ test using the SPSS statistical package as before. All data are expressed as mean $\pm \mathrm{SD}$. The criterion for significance was set at $p<0.05$.

\section{Results}

The characteristics of the human SCI subjects are outlined in Table 1. The age range was 19-86 and the time between injury and death ranged from 2 weeks to 24 years.

Fas-mediated inflammatory response after human SCI

To determine the role of FasL in the modulation of immune reactions involving inflammation, we examined the inflammatory response following human SCI using immunohistochemistry with CD68. We observed a moderate to marked increase in the number of CD68 positive microglia/ macrophages, which showed features typical of activated microglia/macrophages including small, round shapes with short processes, occurring at 2 weeks (Fig. 1b, k), 3 weeks, 4 weeks (acute SCI: 2-4 weeks as see Table 1) and 3.5 months (subacute: 5 weeks to 3.5 months) (Fig. 1c-e) after SCI. However, the number of CD68 positive microglia/ macrophages was decreased at 6 months (Fig. 1f) and 8 months (chronic SCI: over 6 months) (Fig. 1g) post-SCI when compared to 3 weeks (Fig. 1c), 4 weeks (Fig. 1d) and 3.5 months (Fig. 1e). There was a small number of activated microglia and many cells with ramified morphology in the epicenter of the SCI at 2 years and 17 years (Fig. 1h, i) after SCI and control spinal cords (Fig. 1a, j). The number of CD68 positive microglia/macrophages was significantly greater in the compressed epicenter of SCI when compared with normal spinal cords ( $p=0.003$, Fig. 11). As illustrated in Fig. 2b, we found many MMP9 positive cells in the epicenters of spinal cord in acute and subacute SCI but not in control or chronic SCI cases. Moreover, we observed numerous cells which expressed MPO (Fig. 2c), a marker of neutrophils, distributed in the spinal cord parenchyma.

Increased lymphocytic infiltration in the injured human SCI

There was a scattered distribution of CD3 and CD45 positive cells in blood vessels in control and chronic SCI cases. Moreover, in contrast to control cases, there were also numerous CD45 and CD3 positive cells (Fig. 2d, e) randomly distributed in the spinal cord epicenter parenchyma following acute and subacute SCI.

Apoptosis after human SCI

In investigating whether SCI-induced apoptosis occurred by activated caspase-3 and TUNEL as complementary markers of apoptosis (Fig. 3), we observed that most cells which were positive for activated caspase-3 (Fig. 3b, c) or TUNEL (Fig. 3k, 1) were randomly distributed in the 

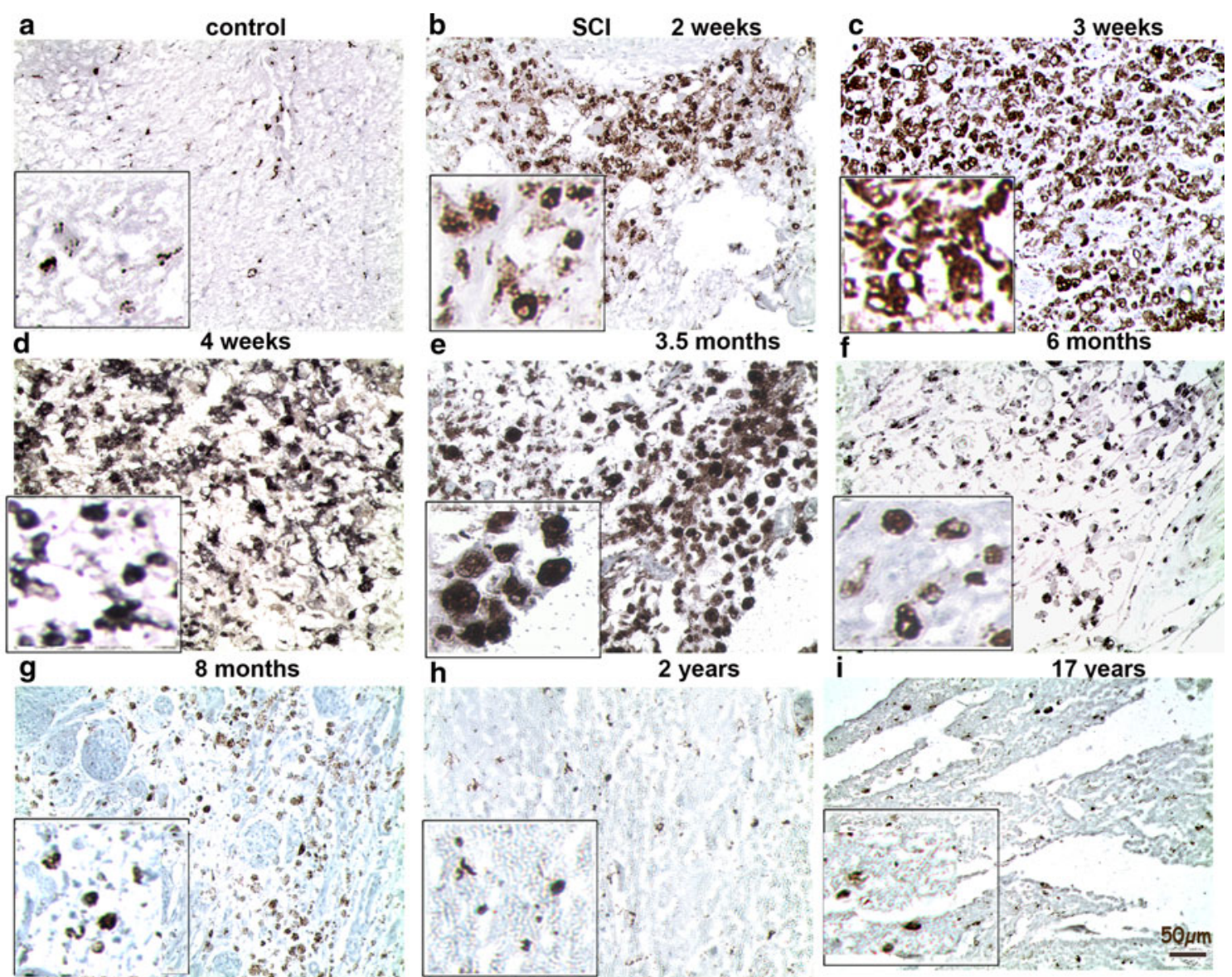

6 months
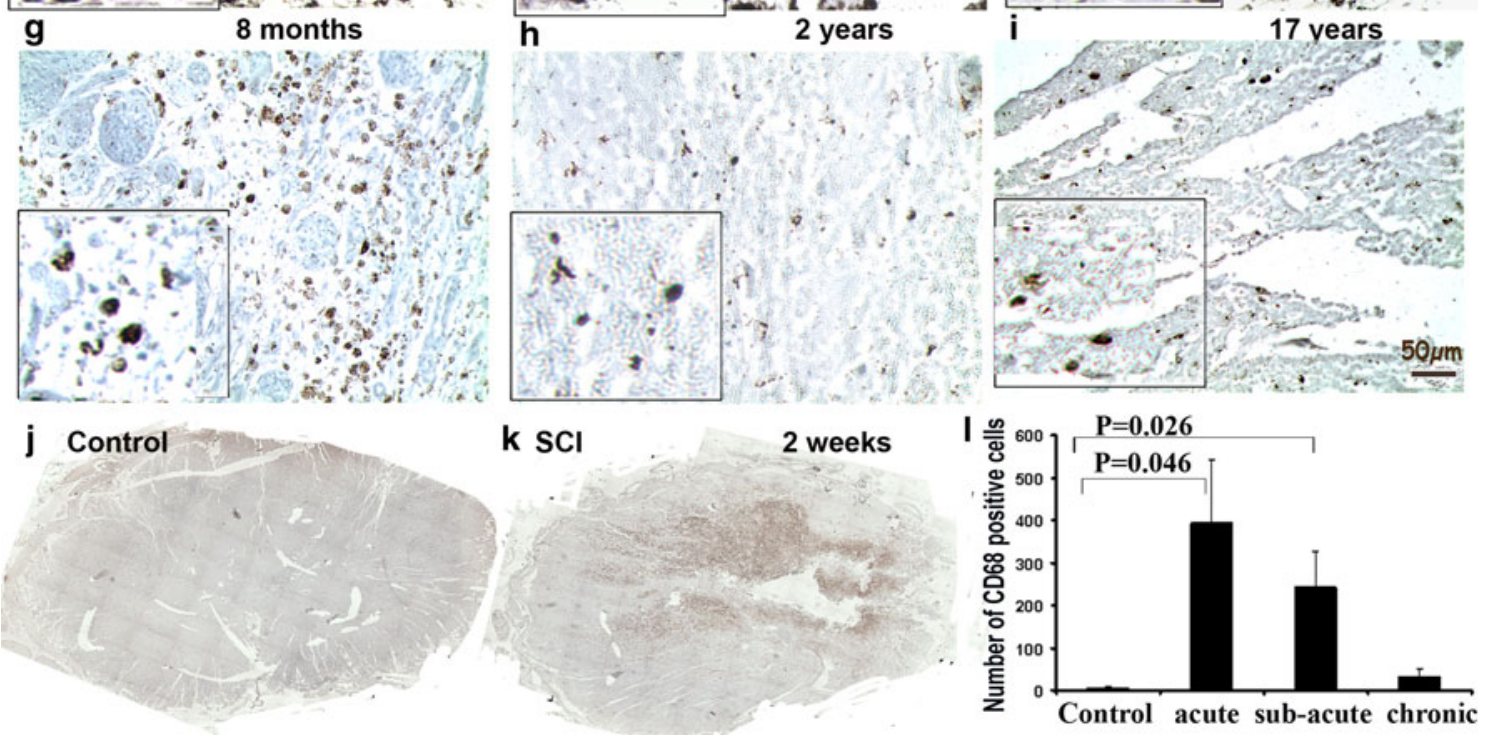

Fig. 1 Accumulation of microglia/macrophages in human SCI. CD68-positive cells in normal control spinal cord $(\mathbf{a}, \mathbf{j})$. There were numerous CD68-positive microglia/macrophages in the epicenter of the injured spinal cord at acute (b and $\mathbf{k} 2$ weeks, c 3 weeks, d 4 weeks) and subacute SCI (e 3.5 months) time points. There was a

epicenter of SCI lesions from 2 weeks to 3.5 months following SCI but not in control cases or following chronic SCI (Fig. 3a, j) and caudal regions of SCI spinal cords. We found activated caspase- 3 positive oligodendrocytes (Fig. 3d), neurons, neutrophils (Fig. 3e) and microglia/macrophages (Fig. 3f) in the injured epicenter of SCI. To look specifically at the apoptotic pathway, we examined the involvement of mitochondria by assessing the activation of caspase- 9 and caspase-7 which are downstream targets of this pathway. We found that activated caspase-9 (Fig. 3g) and caspase-7 (Fig. 3h) were expressed on neurons and glial cells after acute SCI. No significant increase in the number of CD68 positive microglia/ macrophages (I) in the epicenter of acute SCI and subacute SCI when compared to control (a) and chronic SCI (f 6 months, g 8 months, h 2 years and i 17 years)

activated caspase- 9 and caspase- 7 positive cells were seen in control or chronic SCI cases. The quantification of apoptotic cells showed a significant increase in the number of TUNEL-positive cells in the injured epicenter of SCI when compared with chronic SCI and control cases $(P<0.05)$ (Fig. 3i).

Fas/FasL accumulation in the epicenter of human SCI lesions

To test whether spinal cord injury induces Fas/FasL accumulation, we performed immunohistochemistry with 


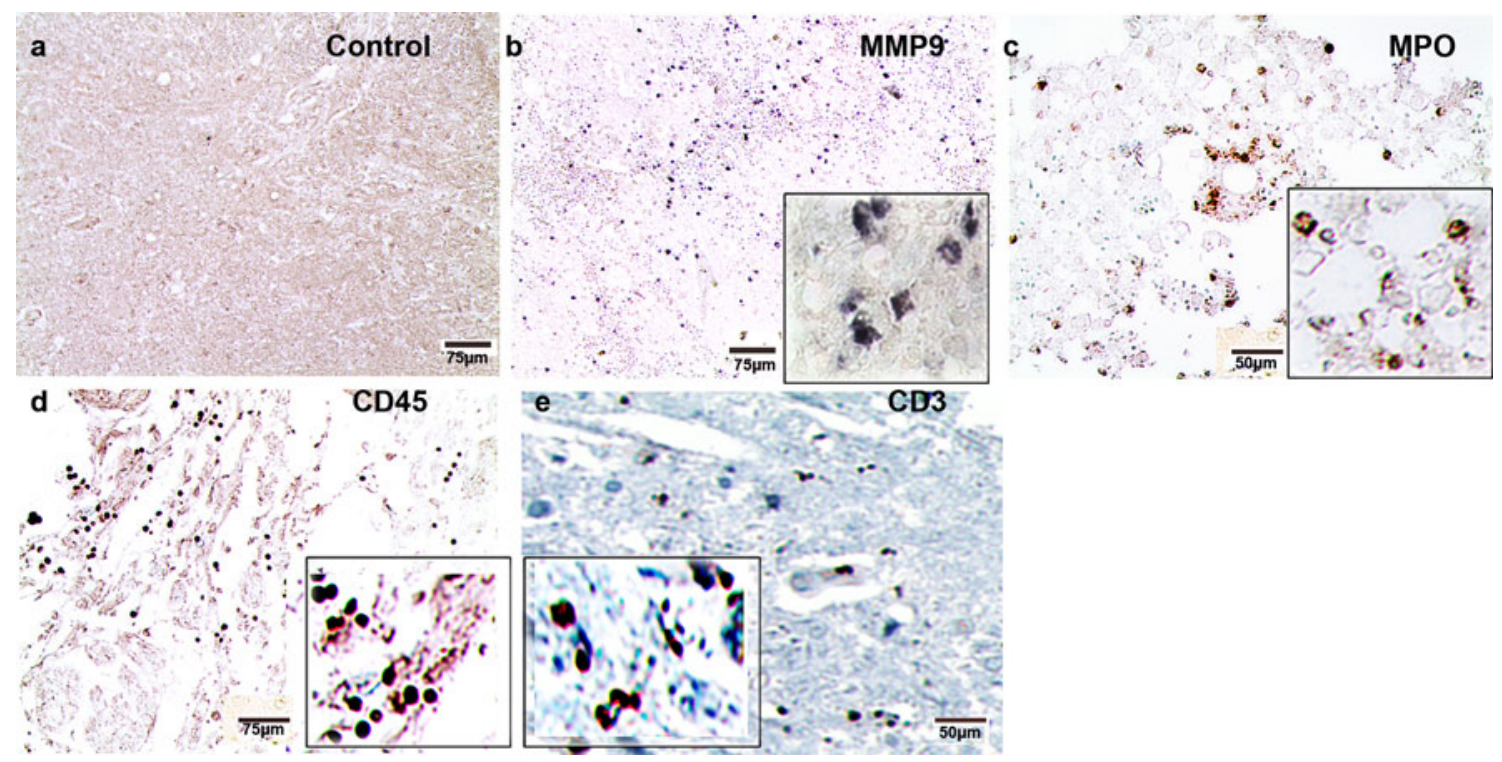

Fig. 2 Increased MMP9, MPO and lymphocytic positive cells after human SCI. There are numerous MMP9 positive cells (b), MPO (c) positive neutrophils, CD45-positive B lymphocytes (d) and CD3 positive T lymphocytes (e) in the epicenter of the spinal cord after SCI when compared to the control case (a)

of SCI in lpr and Wt mice to test Fas-mediated apoptosis, inflammation, gliosis and axonal degeneration. Using immunohistochemistry and Western blotting with GFAP antibody, we observed an increase in GFAP expression after SCI in both $l p r$ mice (Fig. 5c) and Wt mice (Fig. 5b) at 7-70 days post-SCI but not in sham controls (Fig. 5a). However, $l p r$ mice showed a marked attenuation in the expression of GFAP at $3(p=0.003)$ and $14(p=0.012)$ days post-SCI compared with Wt mice as determined by Western blot analysis (Fig. 5d).

Fas-deficient mice exhibit reduced inflammatory cell infiltration after SCI

To confirm the Fas/FasL-mediated inflammation as seen in human SCI, we used immunostaining with microglia/ macrophages (Iba1) and macrophages (F4/80) antibodies following SCI in lpr and Wt mice. We found many Iba1 positive cells with larger, rounded, and short processes, typical of activated macrophages in the degenerated white matter of spinal cords, after SCI from 7 to 70 days in both $l p r$ and Wt mice when compared to sham control (Fig. 5e). There was a significant increase in the number of F4/80 positive macrophages at the injured epicenter of $\mathrm{SCI}$ in $l p r$ mice when compared with the $\mathrm{Wt}$ mice at 3 $(p=0.003), 7 \quad(p=0.012)$ and 70 days post-SCI (not shown). Of note, lpr mice had significantly decreased numbers of short ramified microglia surrounding the injured epicenter when compared with Wt mice in sagittal section using immunostaining with Ibal antibody (not 


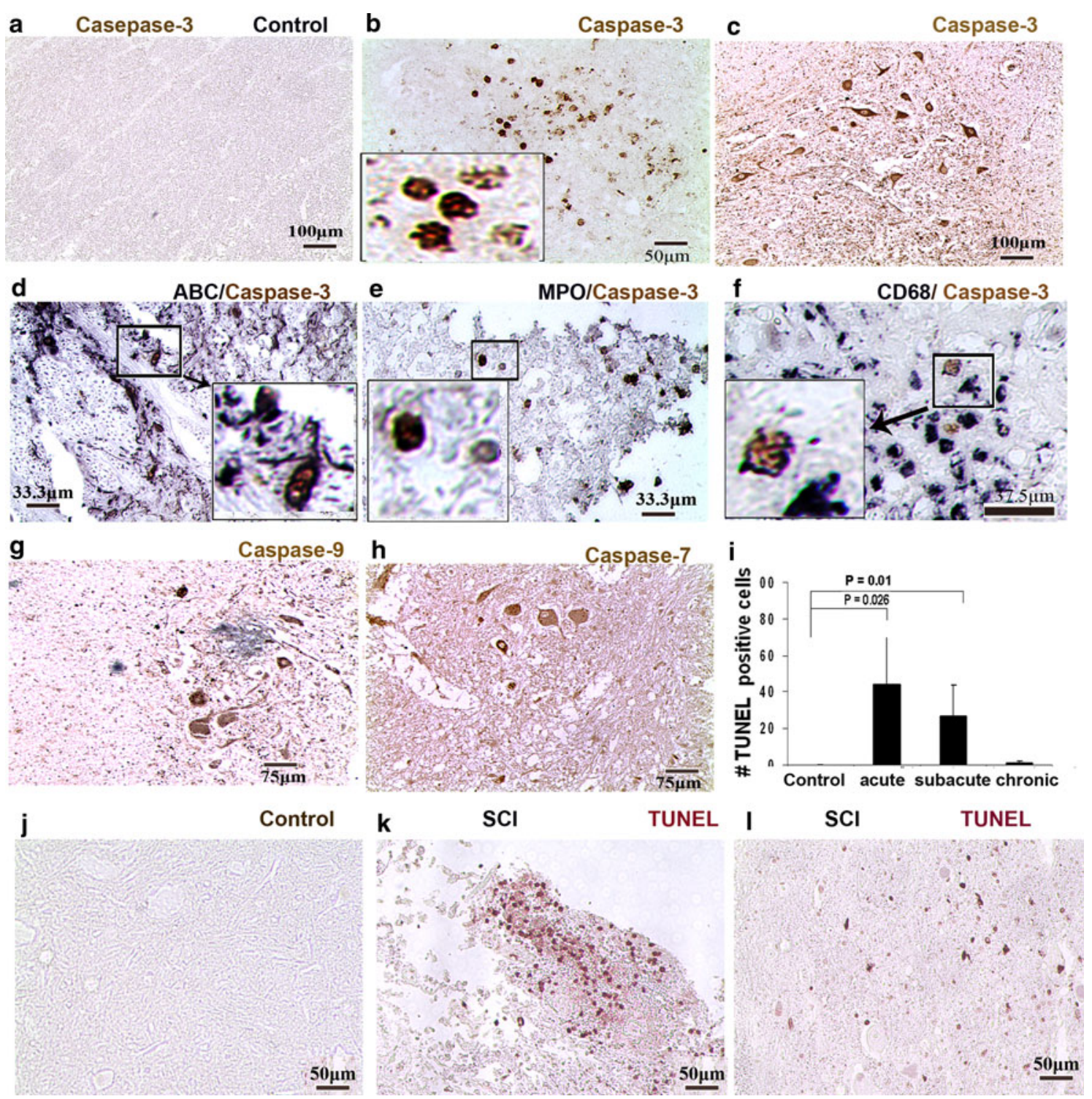

Fig. 3 Apoptosis in human acute SCI. Caspase-3 positive cells (b and c) were observed after acute SCI but not in control spinal cords (a) or chronic SCI. Oligodendrocytes (d APC), neutrophils (e MPO) and microglia/macrophages (f CD68) undergo apoptosis after acute SCI. We also found that activated caspase-9 (g) and caspase-7 (h) were expressed on neurons after acute SCI. There was a

shown). Furthermore, Western blot analysis with Iba1, $\mathrm{NF}-\kappa \mathrm{B}$ and $\mathrm{p}-\mathrm{IKappaB}$ antibodies showed that there was a significant decrease in the level of Ibal expression at 3

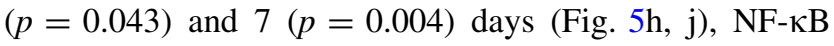
expression at $3(p=0.002)$ and 14 days $(p=0.019)$ (Fig. 5h, k) and p-IKappaB expression (which plays a key role in regulating the immune response to infection) at 7 $(p=0.024), 14$ and 70 days $(p=0.004)$ (Fig. 5i, l) in lpr mice when compared with the Wt mice after SCI, respectively. Moreover, there was significant elevation of MMP2 activation (Fig. 5m, n) in $l p r$ mice when compared significant increase in the number of TUNEL-positive cells at the epicenter after SCI when compared with control cases and chronic SCI (i). Many TUNEL-positive cells were observed in the injury epicenter at 2 weeks (k) and 3.5 months (I) after SCI. No activated caspase-3 and TUNEL-positive cells were seen in control cases $(\mathbf{a}, \mathbf{j})$

with the Wt mice at 7 days post-SCI but not MMP9 activation.

Fas-deficient mice exhibit increased CD4 positive lymphocytes after SCI

Given that Fas/FasL-mediated apoptosis appears to be closely linked with the immune response to trauma, we analyzed the expression of immune cells. Of note, we observed that there was a significantly increased number of CD4 positive lymphocytes present in the injured spinal 


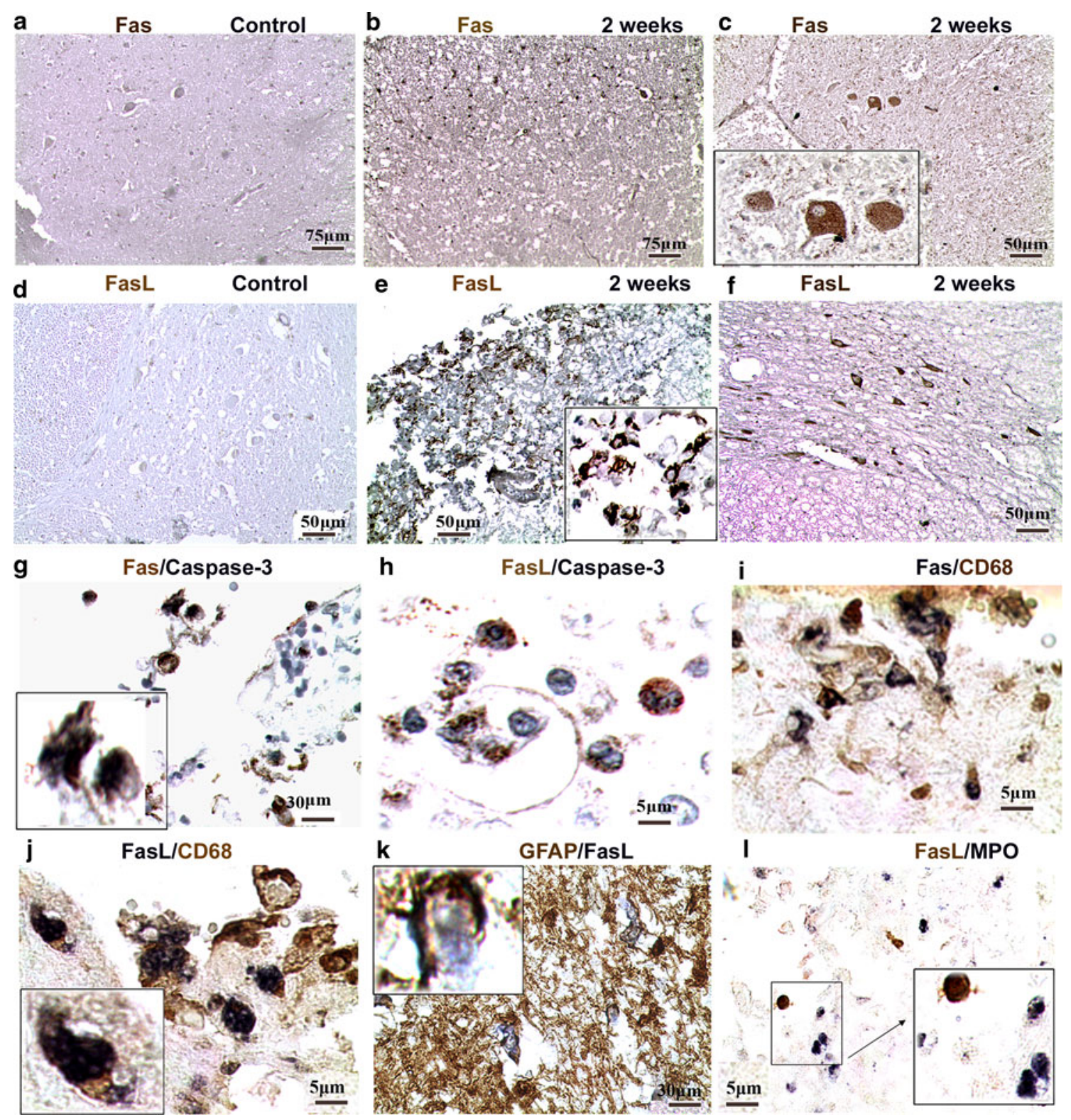

Fig. 4 Fas/FasL-mediated apoptosis and inflammation in human SCI. We found few Fas (a) and FasL (b) positive glial cells in control spinal cords. An increase in the number of Fas (d) and FasL (e) positive glial and Fas (c) and FasL (f) positive neurons was seen at 2 weeks following SCI. There is co-localization of Fas with activated

cord at 7 and 14 days after SCI in $l p r$ mice relative to $\mathrm{Wt}$ mice (Fig. 6a-c).

Fas-deficient mice exhibit increased the levels of anti-inflammatory cytokines and reduced pro-inflammatory cytokines after SCI

There is a correspondence between the extent of microglia/ macrophage reactivity and the elevation of inflammatory cytokines inducing lymphocyte proliferation and neuroinflammatory response after SCI. Using ELISA with Mouse caspase-3 (g), FasL with activated caspase-3 (h), Fas with microglia/ macrophages (i), FasL with microglia/macrophages (j), FasL with astrocytes (k), and FasL with neutrophils (l) in the injured epicenter at 2 weeks after acute SCI

32-plex cytokine/chemokine panel bead immunoassay, we found significantly increased the levels of anti-inflammatory cytokine IL-10 and IL-7 (Fig. 6d, e) expression at 3 days and reduced levels of pro-inflammatory cytokines IL-1alpha, IFN gamma and IL-15 (Fig. 6g-i) at 14 days and IL-6 at 3 days (Fig. 6j) after SCI in $l p r$ mice when compared with Wt mice. We also found a significant increase in the levels of pro-inflammatory cytockines of IL-1alpha, IL-15 and IL-12p40 at 14 days (Fig. 6g, i, k) and IL-6 at 3 days (Fig. 6j) after SCI when compared with sham control in Wt mice. 

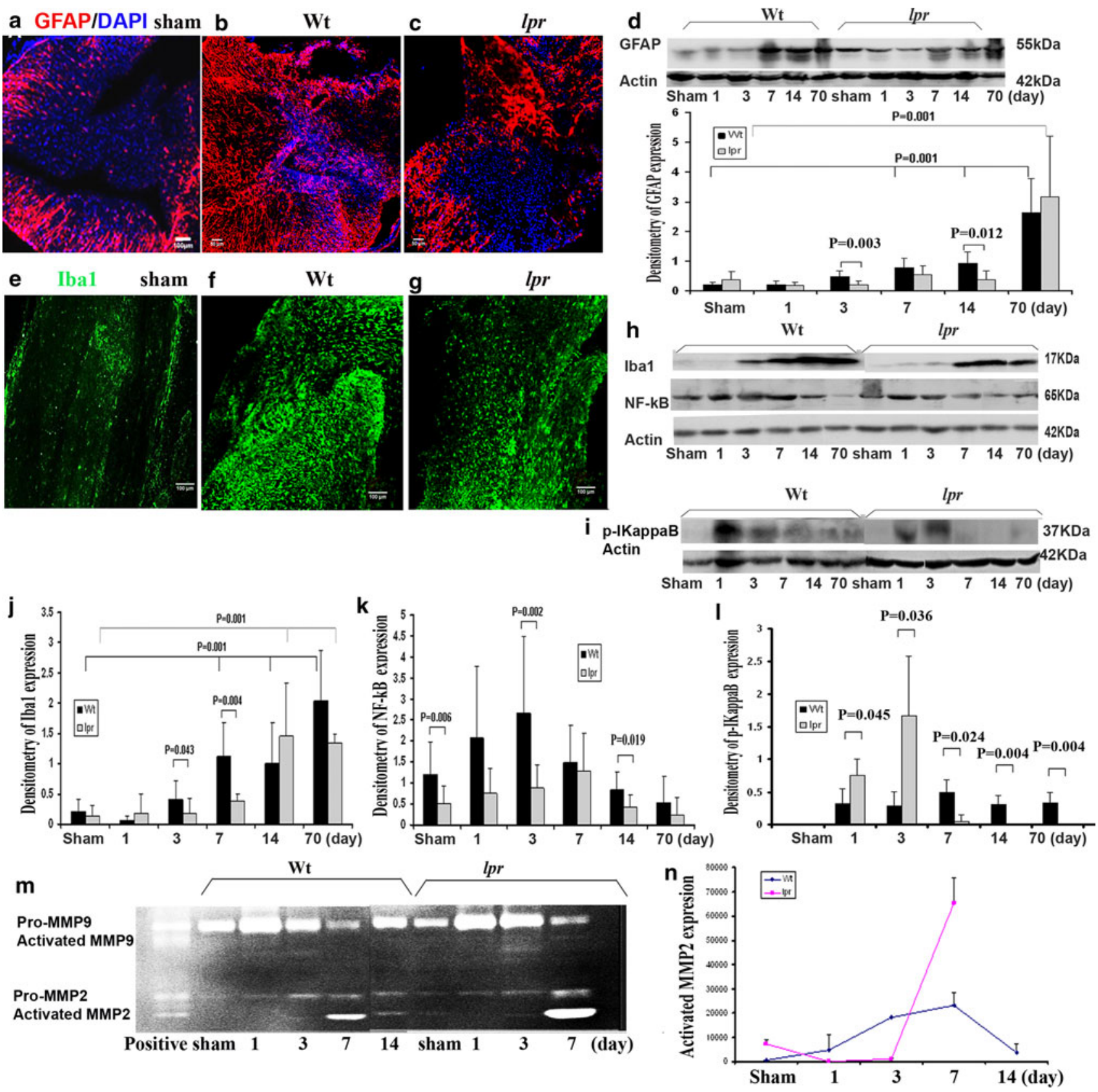

Fig. 5 Fas-deficient mice exhibited reduced glial scar formation and inflammation following SCI. $l p r$ mice showed a significant decrease in the expression of GFAP at 7 days as illustrated by immunostaining [a Wt (sham); b Wt and $\mathbf{c} l p r$ ] and by Western blot analysis (d) when compared to Wt mice at 3 days and 7 days $(p=0.001)$. We also found a significant decrease in the number of Iba1 positive microglia

Fas-deficient mice exhibit reduced chemokines after SCI

The chemokines are involved in a wide variety of processes including acute and chronic types of inflammation and infectious diseases. To confirm Fas/FasL-mediated inflammation involved chemokines after SCI, we used an ELISA with as illustrated by immunostaining [e sham (Wt), f Wt, $\mathbf{g} l p r]$ and densitometry of Iba1 expression by Western blotting in $l p r$ mice relative to $\mathrm{Wt}$ mice $(\mathbf{h}, \mathbf{j})$. Furthermore, there is a significant decrease in NF- $\mathrm{KB}(\mathbf{h}, \mathbf{k})$ and $\mathrm{p}-\mathrm{IKappaB}(\mathbf{i}, \mathbf{l})$ expression and an increase in MMP2 expression $(\mathbf{m}, \mathbf{n})$ in $l p r$ mice relative to $\mathrm{Wt}$ mice following SCI

Mouse 32-plex cytokine/chemokine panel bead immunoassay and found a significant increase in the levels of chemokines of MCP-1 (monocyte chemoattractant protein-1: Fig. 7a), Eotaxin (Fig. 7b), RANTES/CCL5 (regulated upon activation, normal T-cell expressed and secreted: Fig. 7c), MIG (Monokine induced by IFN gamma (Fig. 7d), MIP-1a (macrophage inflammatory protein-1ą: Fig. 7e) at 14 days 

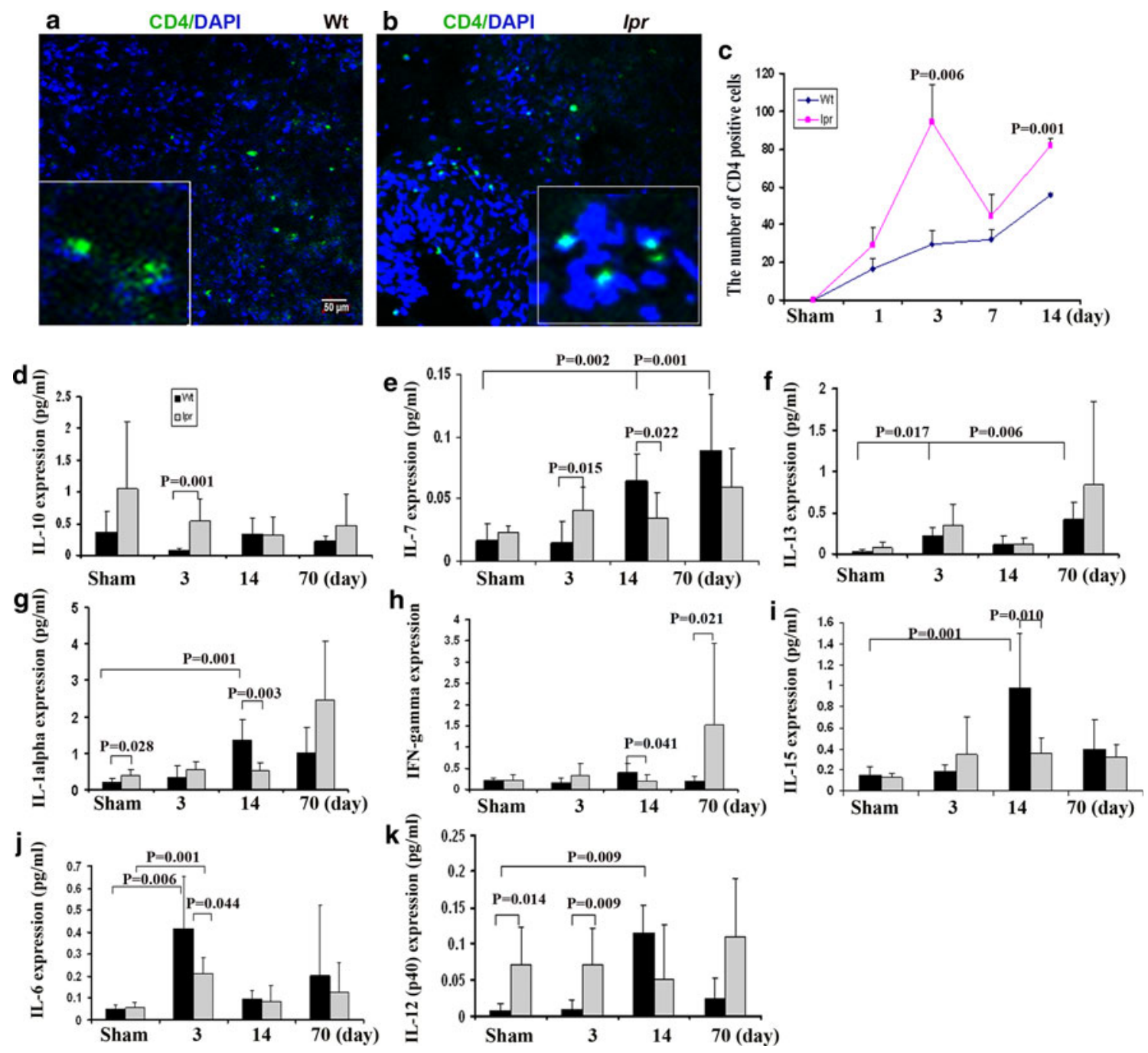

Fig. 6 Increased number of CD4 positive cells and changes of cytokines in $l p r$ mice after SCI. There is a significantly increased number of CD4 positive lymphocytes in the injured spinal cord at 7 and 14 days after SCI in $l p r$ mice $(\mathbf{b}, \mathbf{c})$ relative to Wt mice $(\mathbf{a}, \mathbf{c})$. We observed a significant increase of anti-inflammatory cytokines IL-10 (d) and IL-7 (e) at 3 days in $l p r$ mice when compared with Wt mice after SCI. We furthermore

post-SCI. MIP-2 (Fig. 7f) and M-CSF (Macrophage colonystimulating factor: Fig. $7 \mathrm{~g}$ ) from 3 or 14 to 70 days post-SCI when compared with sham control in Wt mice. Moreover, we found significantly reduced levels of chemokines MCP-1 and Eotaxin (Fig. 7a, b) at 14 days after SCI in lpr mice when compared with Wt mice after SCI. We did not find any differences in G-CSF, IL-1ß, Il-2, IL-9 and VEGF between lpr and Wt mice after SCI (not shown). Moreover, the standard range was exceeded for IL-3, Il-4, IL-5, IL-12p70, ILX, TNF-ą, and GM-CSF (not shown) following SCI in both $l p r$ and Wt mice.

\section{Changes for BDA labeling CST}

To investigate Fas-mediated inflammation in axon regeneration, we examined the long-term outcome and pathology of found a significant reduction in the amount of pro-inflammatory cytokines of IL-1alpha (g), IFN gamma (h) and IL15 (i) at 14 days and IL-6 (j) at 3 days in lpr mice when compared to Wt mice after SCI, but did not see a reduction in IL-13 (f). However, we also found a significant increase in the amount of cytokines IL-12(p-10) (k) at 3 days in lpr mice when compared to Wt mice after SCI

spinal-injured animals in lpr and Wt mice. Sagittal sections containing the lesion revealed prominent BDA labeling of the main CST in the dorsal column and extensive collaterals in the gray matter rostral to the injury (Fig. 8a, b). BDAlabeled axons ended just rostral to the injury site in $l p r$ mice but ended further from the injured site in Wt mice.

\section{Western blotting results}

There was significantly increased $\beta$-III tubulin and NF200 expression at 3,14 and 70 days post-SCI (Fig. 8c-e) and elevation of axonal growth-associated protein MMP2 expression at 7 and 14 days (Fig. 5i, j) post-SCI. Upregulation with chemokine (KC) expression (Fig. 8f, g) was associated with axonal growth at 14 and 70 days post-SCI 

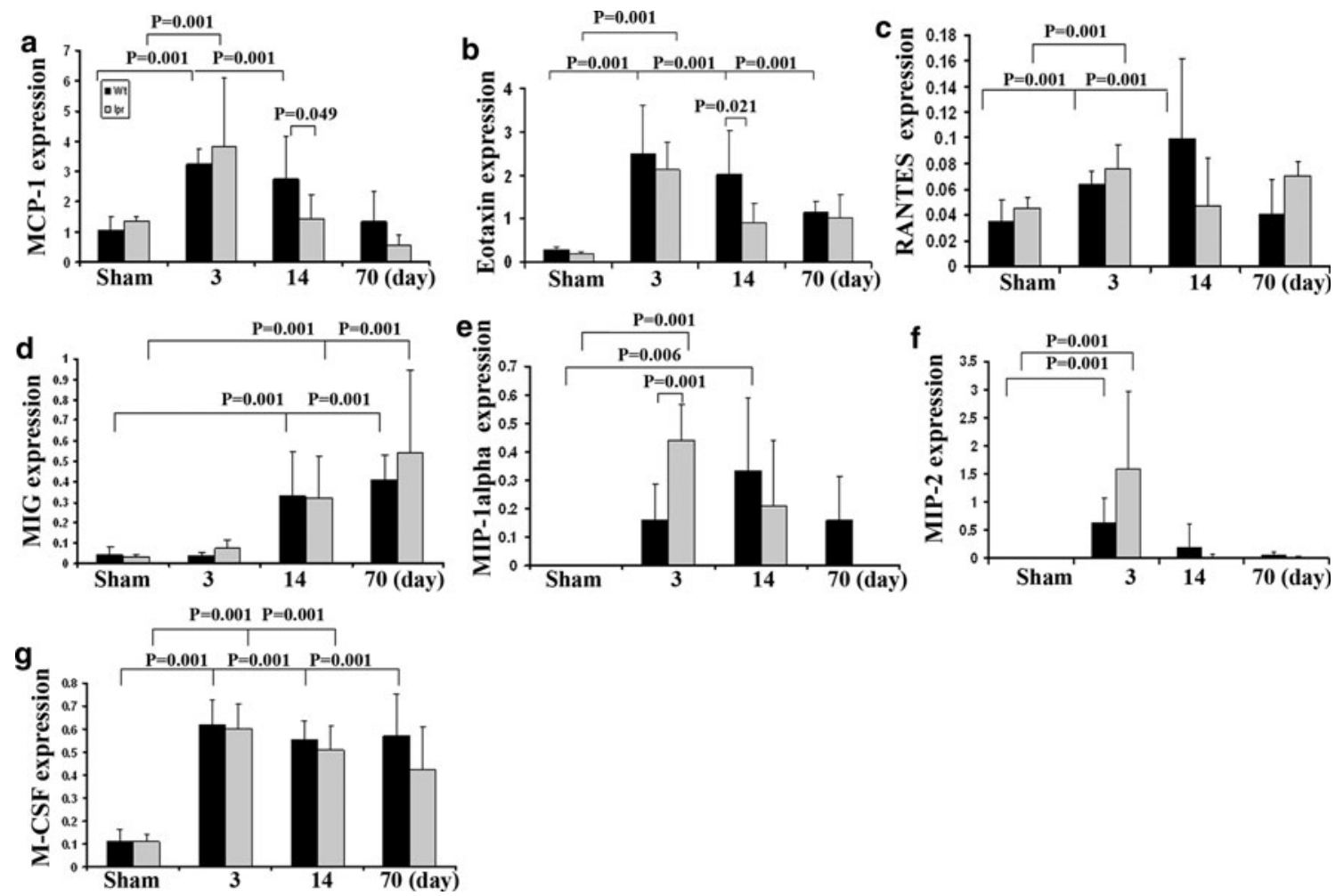

Fig. 7 Changes in levels of chemokines following SCI. We observed an increase in the chemokines MCP-1(a), Eotaxin (b), RANTES (c), MIG (d), MIP-1ą eotaxin (e), MIP-2 (f) and M-CSF (g) following SCI

when compared with sham controls in $l p r$ mice. There were also no significant differences in MAP2, CNPase and MBP expression (Fig. 8i, j) as assessed by Western blotting with MAP2, CNPase and MBP antibodies.

Fas-deficient mice exhibit decreased neurological dysfunction after SCI

To determine if the increased $\beta$-III tubulin and NF200 expression in the $l p r$ mice would support improved functional recovery, the mice were tested using the BMS open field locomotor test and compared with Wt mice. A normal BMS score for mice, before injury, is 9. The locomotor performance of the $l p r$ mice was consistently better than that of the Wt mice $(p=0.001)$. These significant differences were retained until the end point of evaluation in BMS scores of both groups at 70 days post-SCI (Fig. 8k). The average score of the $l p r$ mice at 70 days was $3.087 \pm 0.191$, while the average score of the Wt mice over the same time points was $1.583 \pm 0.204$.

\section{Discussion}

We report novel evidence showing a role for Fas/FasL in apoptosis of neurons and oligodendrocytes and the in both Wt and lpr mice. We found a significant reduction in MCP-1 and Eotaxin expression only at 14 days in $l p r$ mice when compared to Wt mice after SCI

inflammatory response in human SCI. To provide a mechanistic basis for these findings, we determined that Fas-deficient mice with SCI exhibit a significant reduction in the infiltration of inflammatory cells (microglia/macrophages), reduction in the level of GFAP and p-IKappaB expression and release of cytokines and chemokines as compared with Wt controls. Importantly, recovery of locomotor function is facilitated in Fas-deficient mice when compared with Wt mice after SCI. These data strongly suggest that targeting the Fas pathway is an attractive therapeutic target following SCI.

A growing body of evidence indicates that Fas-mediated neuronal and oligodendrocyte apoptosis and inflammation contribute to demyelination and Wallerian degeneration, and thereby affect neuronal function and survival, in the pathobiology of SCI [1, 2, 5, 12, 16, 19, 41, 44]. We and others have shown that neuronal, oligodendrocyte and microglia apoptosis, through activation of the Fas death receptor pathway is a key event $[12,15,16,43,44,47]$ following SCI in animal models. Davis reported that SCI resulted in FasL and Fas translocation into membrane raft microdomains where Fas associates with the adaptor proteins Fas-associated death domain, caspase-8, cellular FLIP long form, and caspase-3, forming a death-inducing signaling complex [15]. Fas deficiency [11, 44], the application of soluble Fas receptor [1] and neutralization of 

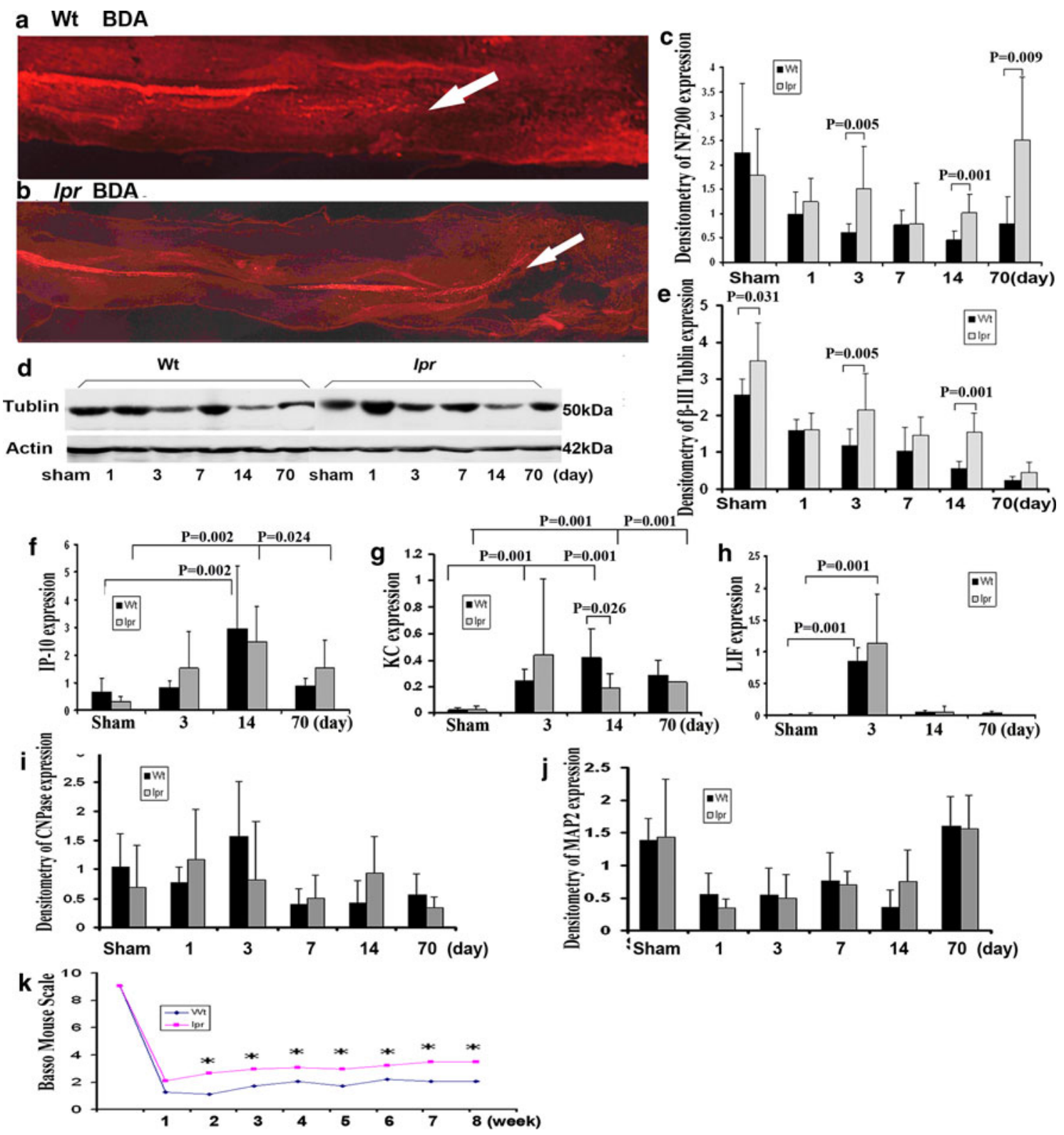

Fig. 8 Fas-deficient mice show reduced axonal degeneration and neurological dysfunction following SCI. BDA-labeled CST axons ended just rostral to the injury site in $l p r$ mice (a) but further away in relation to the injured site in Wt mice (b). We found elevated expression of NF200 (c), $\beta$-III tubulin (d, e) and growth-associated

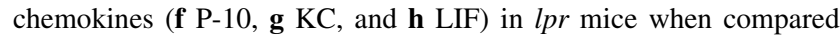
with Wt mice. However, we no found difference in CNPase (i) and MAP2 (j) expression as assessed by Western blotting with CNPase and MAP2 antibodies. There is a significant difference in BMS scale (k) between $l p r$ mice and Wt mice

endogenous FasL [16, 45] have decreased apoptosis and improved functional recovery. The increased expression of Fas and FasL after SCI [12, 16, 44, 47] results in the continued activation of microglia and the inflammatory response to injury, inducing a cascade of apoptotic cell death [4], contributing to demyelination and Wallerian degeneration and thereby affecting neuronal function and survival. Consistent with previous findings that oligodendrocyte and neuronal apoptosis was detected in Wallerian degenerating areas at $6 \mathrm{~h}$ to 3 weeks post-injury in animal models and in a lesion epicenter from 0-3.5 months following humans SCI, we demonstrated an increased caspase-3, 7 and 9 activation, TUNEL, Fas and FasL positive cells in injured epicenter following human acute and subacute SCI but not in chronic SCI or in control cases. We report new evidence that confirms Fas/FasL-mediated apoptosis and which shows Fas/FasL co-localization with activated caspase-3 in the injured epicenter of SCI suggesting Fas-mediated apoptosis plays an important role in neuronal degeneration following SCI. Thus these data 
provide evidence that the functional neurological deficits after SCI are associated with loss of neurons, oligodendrocytes, and demyelination.

SCI elicits an inflammatory response involving resident microglia and infiltration of neutrophils, monocytes/macrophages, and lymphocytes into the lesion from the systemic immune system [22, 35]. Activated microglia/ macrophages were found in the spinal cord from 5 days to 4 months [10] and a year after human SCI [21]. We produced similar results which show that activated microglia/ macrophages were the predominant inflammatory cell type in all cases of SCI from 2 weeks to 6 months at injured epicenter but not in rostral and caudal regions following human SCI. We also found co-localization of Fas/FasL on macrophages, neutrophils and astrocytes in the epicenter of SCI suggesting Fas-mediated inflammation following human SCI.

The inflammatory response may be beneficial, reflecting the role of inflammation as a host defense response to injury and promoting the regeneration of surviving neurons or it may release toxic factors that amplify tissue damage which can lead to poor functional recovery following SCI [37]. Letellier et al. [31] reported that lack of FasL on CNS resident neural cells reduces the initial infiltration of inflammatory cells, creating an inflammatory response after SCI. However, the molecular mechanism by which Fas induces inflammation has remained elusive. To further confirm Fas/FasL-mediated apoptosis and inflammation occurring in human SCI, we used the Fejota ${ }^{\mathrm{TM}}$ clip compression model of SCI in vivo in $l p r$ and $\mathrm{Wt}$ mice at 8 weeks. Consistent with previous finding in our own research and that of others, there was a significantly reduced level of caspase-3 and 9 activation following SCI in $l p r$ mice relative to $\mathrm{Wt}$ mice [11]. In the present study, we present new findings showing a reduction of GFAP, iba1, NF- $\kappa \mathrm{B}$ and p-IKappaB expression and activated microglia in the injury epicenter and decreased neurological dysfunction following SCI in $l p r$ mice relative to $\mathrm{Wt}$ mice. These results suggest that Fas has the potential to reduce the extent of secondary damage by interacting with microglia and leukocytes in the following ways: (1) inhibiting microglia activation thereby reducing proinflammatory cytokine production resulting in restricted neutrophil infiltration and suppressed inflammatory responses. (2) inhibiting GFAP expression which promotes axonal regeneration as we found a significant increase in levels of NF200 and $\beta$-III tubulin and improved neurological function recovery in $l p r$ mice relative to $\mathrm{Wt}$ mice following SCI. (3) increasing MMP-2 promoted functional recovery after injury by regulating the formation of glial scarring and whitematter sparing and/or axonal plasticity [23]. These findings provide a better understanding of the inflammatory mechanisms after SCI. The results further suggest that neutralization of Fas reduces the initial infiltration of inflammatory cells and apoptosis, creating an inflammatory response that facilitates recovery of locomotor function after SCI. There are conflicting results relating to the lack of Fas on CNS resident neural cells reducing apoptosis and improving neurological function recovery in $l p r$ mice following SCI. We [11] and others [44] have shown that Fas deficiency and competitive inhibition of Fas activation [1] can reduce apoptosis [45] and promote neurobehavioral recovery in animal models of SCI. In contrast, Letellier et al. [31] reported that Fas deficient mice do not show decreased caspase- 3 activity or improved functional recovery following SCI. There are several factors contributing to these conflicting results in lpr mice following SCI. First, Letellier et al. [31] used Fasfloxed mice with a Nestin-Cre background at 17.5 weeks. lpr mice develop a lymphoproliferative disorder at ages greater than 18 weeks. In contrast, we used B6.MRL-Fas$l p r$ mice with a $\mathrm{C} 57 \mathrm{Bl} / 6 \mathrm{~J}$ background at 8 weeks of age to avoid this potentially confounding feature, which develops later and less severely in this strain [42]. Second, we used a different model of SCI to Letellier which could contribute to differing results.

Pro-inflammatory cytokines/chemokines are strongly implicated in regulating neutrophil infiltration [18]. Lacroix reported that enhanced IL-6 signaling after SCI results in a sixfold increase in neutrophil infiltration and expanded the neural damaged area [30]. The administration of a mixture of pro-inflammatory cytokines (IL- $1 \mathrm{~b}, \mathrm{IL}-6$. and $\mathrm{TNFa}$ ) at the acute phase of SCI has been shown to provoke an increase in the recruitment of leukocytes to the lesion site [29]. The rise of cytokines is transient from $15 \mathrm{~min}$ to 5 days as levels return to base level after spinal cord injury in rats, humans and mice thus establishing the fact that a short lived burst of inflammatory cytokines is a feature of SCI across several species [29, 36, 40]. A systematic study that documents the acute and chronic evolution of families of inflammatory molecules is lacking. In the present study, to test the release of pro-inflammatory mediator (cytokines and chemokines) as regulators of the infiltration of leukocytes and macrophages into the injured spinal cord, we analyzed the release of cytokines and chemokines in sham controls, 3, 14 and 70 days following $\mathrm{SCI}$ in $l p r$ and Wt mice. We first reported on 32 cytokine and chemokines derived from same sample and from different time points following SCI in both lpr and Wt mice. Importantly, we show a significant increase of inflammatory mediators: cytokines (IL-1alpha, IL-12p40, IL-7 and IL-15 at 14 days and IL-7 and IL-13 at 70 days) in Wt mice after SCI. The rise of chemokines lasts even longer than that of cytokines from 3 to 70 days after spinal cord injury in both $l p r$ and Wt mice. Our results show reduced chemokine expression and increased anti-inflammatory 
cytokines IL-10 may be contributing to better BMS score in $l p r$ mice than $\mathrm{Wt}$ mice following SCI. These findings are consistent with Bethea [8] who reported that systemically administered interleukin-10 reduces tumor necrosis factor-a production significantly improves functional recovery following traumatic SCI in rats.

In conclusion, we report novel evidence showing that Fas/FasL-mediated apoptosis of neurons and oligodendrocytes and inflammation contributes to the pathobiology of spinal cord degeneration and affects neuronal function and survival in human SCI. Fas-deficient mice exhibit significantly reduced infiltration of inflammatory cells (microglia/ macrophages), the level of GFAP and p-IKappaB expression and release of cytokines and chemokines which facilitates recovery of locomotor function when compared with Wt mice following SCI. This work provides a compelling rationale for therapeutically targeting Fas in human SCI.

Acknowledgments This work was supported by the Krembil Chair in Neural Repair and Regeneration. The authors would like to thank Dr. Madeleine O'Higgins for her valuable comments, editing and feedback and Jian Wang for BDA injection.

Open Access This article is distributed under the terms of the Creative Commons Attribution Noncommercial License which permits any noncommercial use, distribution, and reproduction in any medium, provided the original author(s) and source are credited.

\section{References}

1. Ackery A, Robins S, Fehlings MG (2006) Inhibition of Fasmediated apoptosis through administration of soluble Fas receptor improves functional outcome and reduces posttraumatic axonal degeneration after acute spinal cord injury. J Neurotrauma 23:604-616

2. Agarwal S, Gupta S (1999) Increased activity of caspase-3 and caspase- 8 in anti-Fas-induced apoptosis in lymphocytes from ageing humans. Clin Exp Immunol 117:285-290

3. Basso DM, Fisher LC, Anderson AJ, Jakeman LB, McTigue DM, Popovich PG (2006) Basso Mouse Scale for locomotion detects differences in recovery after spinal cord injury in five common mouse strains. J Neurotrauma 23:635-659

4. Beattie MS (2004) Inflammation and apoptosis: linked therapeutic targets in spinal cord injury. Trends Mol Med 10:580-583

5. Beattie MS, Hermann GE, Rogers RC, Bresnahan JC (2002) Cell death in models of spinal cord injury. Prog Brain Res 137:37-47

6. Bethea JR (2000) Spinal cord injury-induced inflammation: a dual-edged sword. Prog Brain Res 128:33-42

7. Bethea JR, Dietrich WD (2002) Targeting the host inflammatory response in traumatic spinal cord injury. Curr Opin Neurol 15:355-360

8. Bethea JR, Nagashima H, Acosta MC, Briceno C, Gomez F, Marcillo AE, Loor K, Green J, Dietrich WD (1999) Systemically administered interleukin-10 reduces tumor necrosis factor-alpha production and significantly improves functional recovery following traumatic spinal cord injury in rats. J Neurotrauma $16: 851-863$
9. Blight AR (1985) Delayed demyelination and macrophage invasion: a candidate for secondary cell damage in spinal cord injury. Cent Nerv Syst Trauma 2:299-315

10. Buss A, Pech K, Kakulas BA, Martin D, Schoenen J, Noth J, Brook GA (2007) Matrix metalloproteinases and their inhibitors in human traumatic spinal cord injury. BMC Neurol 7:17

11. Casha S, Yu WR, Fehlings MG (2005) FAS deficiency reduces apoptosis, spares axons and improves function after spinal cord injury. Exp Neurol 196:390-400

12. Casha S, Yu WR, Fehlings MG (2001) Oligodendroglial apoptosis occurs along degenerating axons and is associated with FAS and p75 expression following spinal cord injury in the rat. Neuroscience 103:203-218

13. Cregan SP, Fortin A, MacLaurin JG, Callaghan SM, Cecconi F, Yu SW, Dawson TM, Dawson VL, Park DS, Kroemer G, Slack RS (2002) Apoptosis-inducing factor is involved in the regulation of caspase-independent neuronal cell death. J Cell Biol 158:507517

14. Crowe MJ, Bresnahan JC, Shuman SL, Masters JN, Beattie MS (1997) Apoptosis and delayed degeneration after spinal cord injury in rats and monkeys. Nat Med 3:73-76

15. Davis AR, Lotocki G, Marcillo AE, Dietrich WD, Keane RW (2007) FasL, Fas, and death-inducing signaling complex (DISC) proteins are recruited to membrane rafts after spinal cord injury. J Neurotrauma 24:823-834

16. Demjen D, Klussmann S, Kleber S, Zuliani C, Stieltjes B, Metzger C, Hirt UA, Walczak H, Falk W, Essig M, Edler L, Krammer PH, Martin-Villalba A (2004) Neutralization of CD95 ligand promotes regeneration and functional recovery after spinal cord injury. Nat Med 10:389-395

17. Desbarats J, Birge RB, Mimouni-Rongy M, Weinstein DE, Palerme JS, Newell MK (2003) Fas engagement induces neurite growth through ERK activation and p35 upregulation. Nat Cell Biol 5:118-125

18. Donnelly DJ, Popovich PG (2008) Inflammation and its role in neuroprotection, axonal regeneration and functional recovery after spinal cord injury. Exp Neurol 209:378-388

19. Emery E, Aldana P, Bunge MB, Puckett W, Srinivasan A, Keane RW, Bethea J, Levi AD (1998) Apoptosis after traumatic human spinal cord injury. J Neurosurg 89:911-920

20. Felderhoff-Mueser U, Taylor DL, Greenwood K, Kozma M, Stibenz D, Joashi UC, Edwards AD, Mehmet H (2000) Fas/ CD95/APO-1 can function as a death receptor for neuronal cells in vitro and in vivo and is upregulated following cerebral hypoxic-ischemic injury to the developing rat brain. Brain Pathol 10:17-29

21. Fleming JC, Norenberg MD, Ramsay DA, Dekaban GA, Marcillo AE, Saenz AD, Pasquale-Styles M, Dietrich WD, Weaver LC (2006) The cellular inflammatory response in human spinal cords after injury. Brain 129:3249-3269

22. Hausmann ON (2003) Post-traumatic inflammation following spinal cord injury. Spinal Cord 41:369-378

23. Hsu JY, McKeon R, Goussev S, Werb Z, Lee JU, Trivedi A, Noble-Haeusslein LJ (2006) Matrix metalloproteinase-2 facilitates wound healing events that promote functional recovery after spinal cord injury. J Neurosci 26:9841-9850

24. Joshi M, Fehlings MG (2002) Development and characterization of a novel, graded model of clip compressive spinal cord injury in the mouse: Part 1. Clip design, behavioral outcomes, and histopathology. J Neurotrauma 19:175-190

25. Joshi M, Fehlings MG (2002) Development and characterization of a novel, graded model of clip compressive spinal cord injury in the mouse: Part 2. Quantitative neuroanatomical assessment and analysis of the relationships between axonal tracts, residual tissue, and locomotor recovery. J Neurotrauma 19:191-203 
26. Kang SM, Hoffmann A, Le D, Springer ML, Stock PG, Blau HM (1997) Immune response and myoblasts that express Fas ligand. Science 278:1322-1324

27. Keane RW, Kraydieh S, Lotocki G, Bethea JR, Krajewski S, Reed JC, Dietrich WD (2001) Apoptotic and anti-apoptotic mechanisms following spinal cord injury. J Neuropathol Exp Neurol 60:422-429

28. Kennedy NJ, Kataoka T, Tschopp J, Budd RC (1999) Caspase activation is required for $\mathrm{T}$ cell proliferation. $\mathrm{J}$ Exp Med 190:1891-1896

29. Klusman I, Schwab ME (1997) Effects of pro-inflammatory cytokines in experimental spinal cord injury. Brain Res 762:173-184

30. Lacroix S, Chang L, Rose-John S, Tuszynski MH (2002) Delivery of hyper-interleukin- 6 to the injured spinal cord increases neutrophil and macrophage infiltration and inhibits axonal growth. J Comp Neurol 454:213-228

31. Letellier E, Kumar S, Sancho-Martinez I, Krauth S, Funke-Kaiser A, Laudenklos S, Konecki K, Klussmann S, Corsini NS, Kleber S, Drost N, Neumann A, Levi-Strauss M, Brors B, Gretz N, Edler L, Fischer C, Hill O, Thiemann M, Biglari B, Karray S, MartinVillalba A (2010) CD95-ligand on peripheral myeloid cells activates Syk kinase to trigger their recruitment to the inflammatory site. Immunity 32:240-252

32. Martin-Villalba A, Herr I, Jeremias I, Hahne M, Brandt R, Vogel J, Schenkel J, Herdegen T, Debatin KM (1999) CD95 ligand (Fas-L/APO-1L) and tumor necrosis factor-related apoptosisinducing ligand mediate ischemia-induced apoptosis in neurons. J Neurosci 19:3809-3817

33. Matsushita K, Wu Y, Qiu J, Lang-Lazdunski L, Hirt L, Waeber C, Hyman BT, Yuan J, Moskowitz MA (2000) Fas receptor and neuronal cell death after spinal cord ischemia. J Neurosci 20:6879-6887

34. Popovich PG, Stuckman S, Gienapp IE, Whitacre CC (2001) Alterations in immune cell phenotype and function after experimental spinal cord injury. J Neurotrauma 18:957-966

35. Popovich PG, Wei P, Stokes BT (1997) Cellular inflammatory response after spinal cord injury in Sprague-Dawley and Lewis rats. J Comp Neurol 377:443-464
36. Rice T, Larsen J, Rivest S, Yong VW (2007) Characterization of the early neuroinflammation after spinal cord injury in mice. J Neuropathol Exp Neurol 66:184-195

37. Rolls A, Shechter R, Schwartz M (2009) The bright side of the glial scar in CNS repair. Nat Rev Neurosci 10:235-241

38. Schwab ME, Bartholdi D (1996) Degeneration and regeneration of axons in the lesioned spinal cord. Physiol Rev 76:319-370

39. Seino K, Kayagaki N, Takeda K, Fukao K, Okumura K, Yagita $\mathrm{H}$ (1997) Contribution of Fas ligand to $\mathrm{T}$ cell-mediated hepatic injury in mice. Gastroenterology 113:1315-1322

40. Streit WJ, Semple-Rowland SL, Hurley SD, Miller RC, Popovich PG, Stokes BT (1998) Cytokine mRNA profiles in contused spinal cord and axotomized facial nucleus suggest a beneficial role for inflammation and gliosis. Exp Neurol 152:74-87

41. Takagi T, Takayasu M, Mizuno M, Yoshimoto M, and Yoshida J (2003) Caspase activation in neuronal and glial apoptosis following spinal cord injury in mice. Neurol Med Chir (Tokyo) 43:20-29 (discussion 29-30)

42. Vidal S, Kono DH, Theofilopoulos AN (1998) Loci predisposing to autoimmunity in MRL-Fas lpr and C57BL/6-Faslpr mice. J Clin Invest 101:696-702

43. Yamaura I, Yone K, Nakahara S, Nagamine T, Baba H, Uchida K, Komiya S (2002) Mechanism of destructive pathologic changes in the spinal cord under chronic mechanical compression. Spine 27:21-26

44. Yoshino O, Matsuno H, Nakamura H, Yudoh K, Abe Y, Sawai T, Uzuki M, Yonehara S, Kimura T (2004) The role of Fas-mediated apoptosis after traumatic spinal cord injury. Spine 29:1394-1404

45. Yu WR, Liu T, Fehlings TK, Fehlings MG (2009) Involvement of mitochondrial signaling pathways in the mechanism of Fasmediated apoptosis after spinal cord injury. Eur J Neurosci 29:114-131

46. Yu WR, Liu T, Kiehl TR, Fehlings MG (2011) Human neuropathological and animal model evidence supporting a role for Fas-mediated apoptosis and inflammation in cervical spondylotic myelopathy. Brain 134:1277-1292

47. Zurita M, Vaquero J, Zurita I (2001) Presence and significance of CD-95 (Fas/APO1) expression after spinal cord injury. J Neurosurg 94:257-264 